\title{
ANALYTICAL SOLUTION TO THE MHD FLOW OF MICROPOLAR FLUID OVER A LINEAR STRETCHING SHEET
}

\author{
P.G. SIDDHESHWAR \\ Department of Mathematics, Bangalore University \\ Central College Campus Bangalore \\ 560001 , INDIA \\ U.S. MAHABALESHWAR* \\ Department of Mathematics \\ Government First Grade College for Women \\ Hassan 573 201, Karnataka, INDIA \\ E-mail: ulavathi@gmail.com
}

\begin{abstract}
The flow due to a linear stretching sheet in a fluid with suspended particles, modeled as a micropolar fluid, is considered. All reported works on the problem use numerical methods of solution or a regular perturbation technique. An analytical solution is presented in the paper for the coupled non-linear differential equations with inhomogeneous boundary conditions.
\end{abstract}

Key words: differential equation, stretching sheet, MHD, micropolar fluid, linear stretching sheet.

\section{Introduction}

The theory of microfluids, as developed by Eringen (1999), has been a field of active research for the last few decades as this class of fluids represents mathematically and physically many industrial applications important fluids like paints, blood, body fluids, polymer, colloidal fluids and suspension. On account of the recent advances in electronics, nuclear energy and space technology, the study of buoyancy induced flows of micropolar fluid still continues to be a major area of interest. The micromotion of fluid elements, spin inertia and the effects of the couple stresses are very important in micropolar fluids. The theoretical study of micropolar fluid flow has important engineering applications in systems having liquids with suspended particles (unclean liquids) as a working medium (see Lukaszewicz, 1999). In micropolar fluids, rigid particles in a small volume element can rotate about the centroid of the volume element. The micropolar fluids in fact can predict behavior at microscale and rotation is independently explained by a microrotation vector.

To the knowledge of the author no paper has presented an analytical solution to the stretching sheet boundary layer flow of a micropolar liquid. Even numerical works tackling this important problem are very sparse (see Heruska et al., 1986; Agarwal et al., 1989; Hassanien and Gorla, 1990; Hady, 1996; Hassanien, 1998; Mahammadein and Gorla, 2000; Kelson and Desseaux, 2001; Kelson and Farrell, 2001; Seddeek, 2001; Abo- Eldahab and Ghonaim, 2003; Bhargava et al., 2003; Nazar et al., 2004; Eldabe et al., 2005).

\footnotetext{
" To whom correspondence should be addressed
} 
The present study throws light on the analytical solution of a class of boundary layer equations arising in the stretching sheet problem involving coupled nonlinear differential equations that typically arise in one more stretching sheet boundary layer flows.

\section{Mathematical formulation and solution}

A steady, incompressible micropolar liquid that is coerced to flow by a horizontal sheet stretching in the $x$-direction (see Fig.1) is considered.

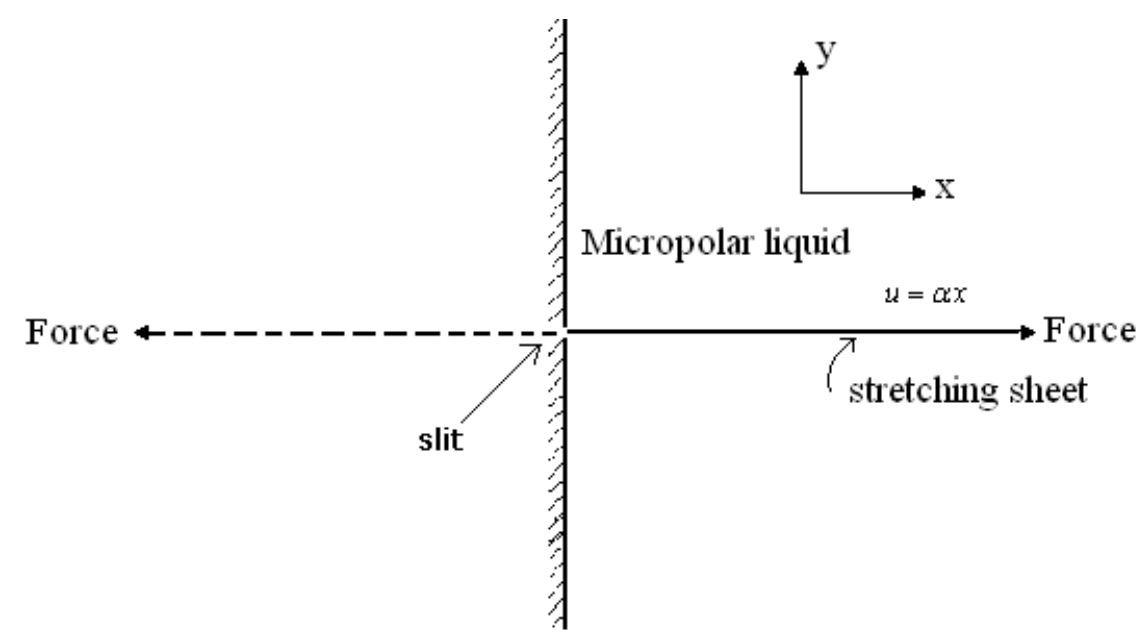

Fig.1. Schematic of the stretching sheet problem.

The liquid issues from a thin slit as is seen in polymer extrusion processes (Rajagopal et al., 1984; Siddheshwar and Mahabaleswar, 2005). The sheet is supposedly stretched in the $x$-direction such that the $x$-component of velocity varies linearly with $x$ along its surface. In practice, it is only an extremely meticulous pulling of the sheet that can allow one to assume linear stretching. The flow is subjected to a uniform transverse magnetic field $H_{0}$ along the $y$-axis. The induced magnetic field can be neglected, since the magnetic Reynolds number is assumed to be very small. The governing equations for the considered micropolar liquid flow within the boundary layer approximation may be written as (see Seddeek, 2001)

$$
\begin{aligned}
& \frac{\partial u}{\partial x}+\frac{\partial v}{\partial y}=0 \\
& u \frac{\partial u}{\partial x}+v \frac{\partial u}{\partial y}=v \frac{\partial^{2} u}{\partial y^{2}}+k_{1} \frac{\partial \omega}{\partial y}-\frac{\sigma H_{0}^{2}}{\rho} u \\
& G_{1} \frac{\partial^{2} \omega}{\partial y^{2}}-2 \omega-\frac{\partial u}{\partial y}=0
\end{aligned}
$$

where the quantities have their meaning as mentioned in nomenclature. The boundary conditions are given by 


$$
\begin{aligned}
& u(x, 0)=\alpha x, \quad v(x, 0)=0, \\
& \omega(x, 0)=\bar{s}\left(\omega(x, 0)+\frac{1}{2} \frac{\partial u}{\partial y}(x, 0)\right), \\
& u(x, \infty) \rightarrow 0, \\
& \frac{\partial \omega}{\partial y}(x, \infty) \rightarrow 0
\end{aligned}
$$

where $\bar{s}$ is a parameter relating the microrotation to the asymmetric part of the stress with $0 \leq \bar{s}<\infty$. The condition on $\omega(x, 0)$ in Eqs (2.4) reduces to no relative spin and no asymmetric part of the stress on the boundary in the limit $\bar{s} \rightarrow 0$ and $\bar{s} \rightarrow \infty$ respectively. We now define the following dimensionless variables

$$
(X, Y)=\sqrt{\frac{\alpha}{v}}(x, y), \quad(U, V)=\frac{(u, v)}{\sqrt{\alpha v}}, \quad N^{*}=\frac{\omega}{\alpha}, \quad k_{2}=\frac{k_{1}}{v}, \quad G_{2}=\frac{\alpha G_{1}}{v},
$$

and substituting the same in Eqs (2.1)-(2.4) yields

$$
\begin{aligned}
& \frac{\partial U}{\partial X}+\frac{\partial V}{\partial Y}=0, \\
& U \frac{\partial U}{\partial X}+V \frac{\partial U}{\partial Y}=\frac{\partial^{2} U}{\partial Y^{2}}+k_{2} \frac{\partial N^{*}}{\partial Y}-Q U, \\
& G_{2} \frac{\partial^{2} N^{*}}{\partial Y^{2}}-2 N^{*}-\frac{\partial U}{\partial Y}=0, \\
& U(X, 0)=X, \quad V(X, 0)=0, \\
& N^{*}(X, 0)=\bar{s}\left(N^{*}(X, 0)+\frac{1}{2} \frac{\partial U}{\partial Y}(X, 0)\right), \\
& U(X, \infty) \rightarrow 0, \\
& \frac{\partial N^{*}}{\partial Y}(X, \infty) \rightarrow 0 .
\end{aligned}
$$

The various parameters in Eqs (2.6)-(2.9) are as defined in nomenclature.

The stream function $\psi(X, Y)$ is now introduced in Eqs (2.6)-(2.9) to obtain the following equations 


$$
\begin{aligned}
& \frac{\partial^{3} \psi}{\partial Y^{3}}+\frac{\partial\left(\psi, \psi_{y}\right)}{\partial(X, Y)}+k_{2} \frac{\partial N^{*}}{\partial Y}-Q \frac{\partial \psi}{\partial Y}=0, \\
& G_{2} \frac{\partial^{2} N^{*}}{\partial Y^{2}}-2 N^{*}-\frac{\partial^{2} \psi}{\partial Y^{2}}=0, \\
& \frac{\partial \psi}{\partial Y}(X, 0)=X, \quad-\frac{\partial \psi}{\partial X}(X, 0)=0, \\
& N^{*}(X, 0)=\bar{s}\left(N^{*}(X, 0)+\frac{1}{2} \frac{\partial^{2} \psi}{\partial Y^{2}}(X, 0)\right) \\
& \frac{\partial \psi}{\partial Y}(X, \infty) \rightarrow 0 \\
& \frac{\partial N^{*}}{\partial Y}(X, \infty) \rightarrow 0 .
\end{aligned}
$$

The above boundary value problem (BVP) suggests the solution of the form

$$
\begin{aligned}
& \psi(X, Y)=X f(Y), \\
& N^{*}(X, Y)=X h(Y) .
\end{aligned}
$$

Substituting Eqs (2.13) and (2.14) in Eqs (2.10)-(2.12) and equating the coefficients of $X, X^{2}$ and $X^{3}$, yields the following BVP

$$
\begin{aligned}
& \frac{d^{3} f}{d Y^{3}}+f \frac{d^{2} f}{d Y^{2}}-\left(\frac{d f}{d Y}\right)^{2}+k_{2} \frac{d h}{d Y}-Q \frac{d f}{d Y}=0, \\
& G_{2} \frac{d^{2} h}{d Y^{2}}-2 h-\frac{d^{2} f}{d Y^{2}}=0, \\
& f(0)=0, \quad \frac{d f}{d Y}(0)=1, \quad \frac{d f}{d Y}(\infty) \rightarrow 0, \\
& h(0)=-S \frac{d^{2} f}{d Y^{2}}(0), \quad h(\infty) \rightarrow 0
\end{aligned}
$$

where 
$S=\frac{\bar{s}}{2(\bar{s}-1)}$ and $0 \leq S \leq 1 / 2$. The solution of Eqs (2.15) and (2.16), subject to the conditions in Eqs (2.17), can be obtained by following the new analytical method as

$$
\begin{aligned}
& f(Y)=\frac{1-e^{-s_{1} Y}}{s_{1}}, \\
& h(Y)=S s_{1} e^{-s_{I} Y}
\end{aligned}
$$

where

$$
s_{I}=\sqrt{(1+Q)+\frac{k_{2}}{G_{2}}(2 S-1)} .
$$

The parameter $s_{1}$ is an important one.

\section{Results and discussion}

In the paper the MHD boundary layer flow and heat transfer in a micropolar liquid over a stretching sheet is investigated. Similarity solution is used to obtain the velocity distribution and spin which are governed by non-linear differential equations. The velocity, both transverse as well as axial, is a decreasing function of $Y$ (transverse coordinate) as it is an exponential function with negative argument. It is clear from Eq.(2.18) that the argument of the exponential function involves an important parameter of the problem namely $s_{1}$ which is a function of the coupling coefficient $k_{2}$, microrotation diffusivity parameter $G_{2}$, Chandrasekhar number $Q$, and microrotation concentration coefficient $S$. Before proceeding with the discussion of results obtained in the paper, the following needs to be noted

$$
U=X f^{\prime}(Y), \quad V=-f(Y)
$$

Figure 2 shows the variation of $f^{\prime}(Y)$ with $Y$ for different values of $Q$. As seen earlier, $f^{\prime}(Y)$ and $f(Y)$ are respectively related to the axial velocity $U$ and transverse velocity $V$. In Fig.2 we see that $U$ is an exponentially decaying function of $Y$ and the effect of increasing $Q$ is to restrict the dynamics to the vicinity of the stretching sheet. In Fig.3 the nature of $f^{\prime}(Y)$, as seen in Fig.2, is reiterated. Figure 3 shows the variation of $f^{\prime}(Y)$ with $Y$ for different values of $S$. As documented in nomenclature the parameter $S$ has to do with the boundary condition on the spin. From the figure it is apparent that the effect of increasing $S$ is to decrease $U$. A similar effect of $G_{l}$ on $f^{\prime}(Y)$ is shown in Fig.4. The effect of increasing $k_{2}$ on $f^{\prime}(Y)$ is opposite to that of increasing $G_{l}$ on $f^{\prime}(Y)$. This is shown in Fig.5. 


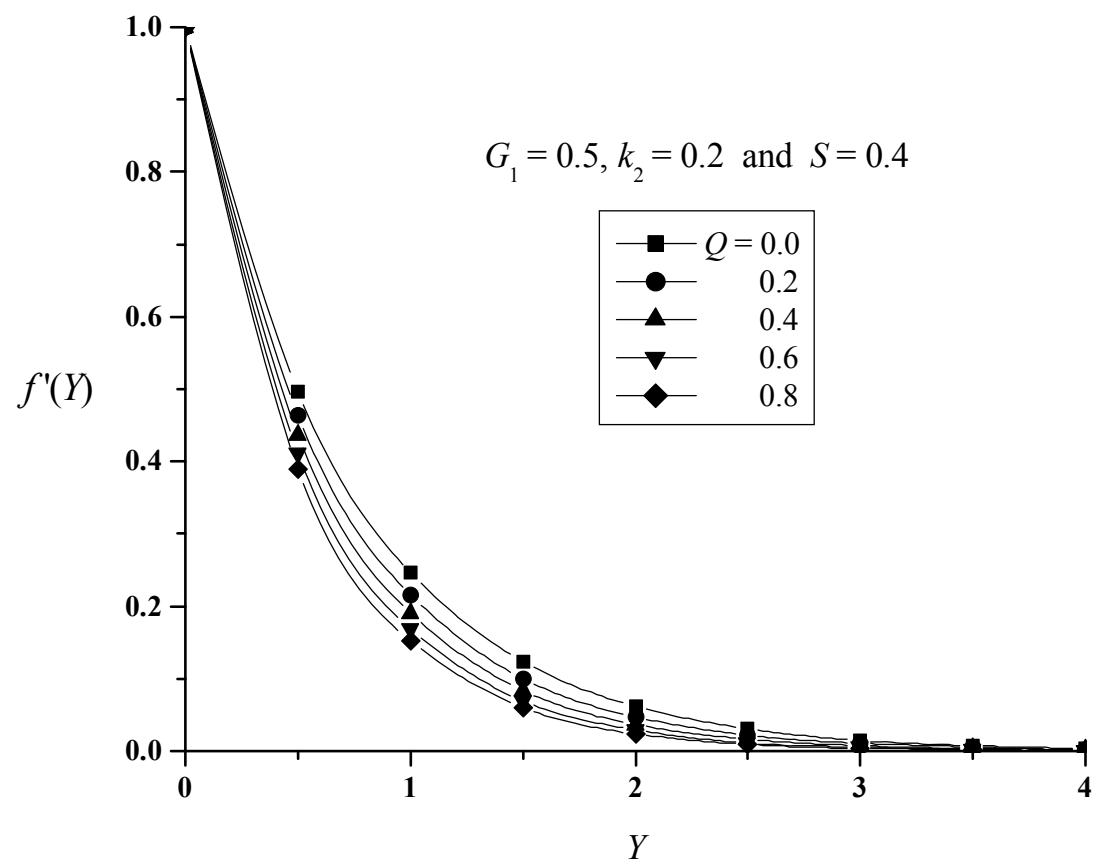

Fig.2. Plot of $f^{\prime}(Y)$ versus $Y$ for different values of Chandrasekhar number Q.

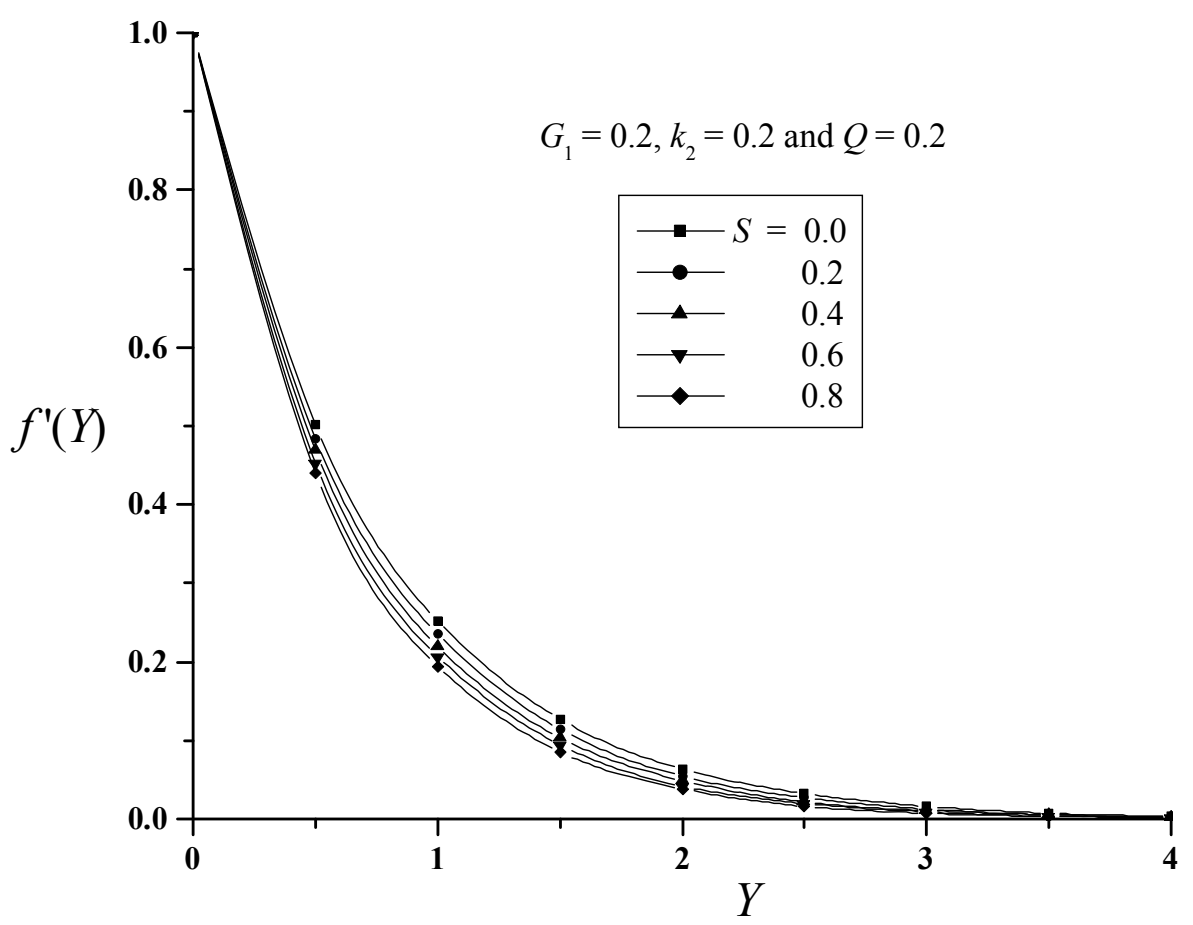

Fig.3. Plot of $f^{\prime}(Y)$ versus $Y$ for different values of microrotation concentration coefficient $S$. 


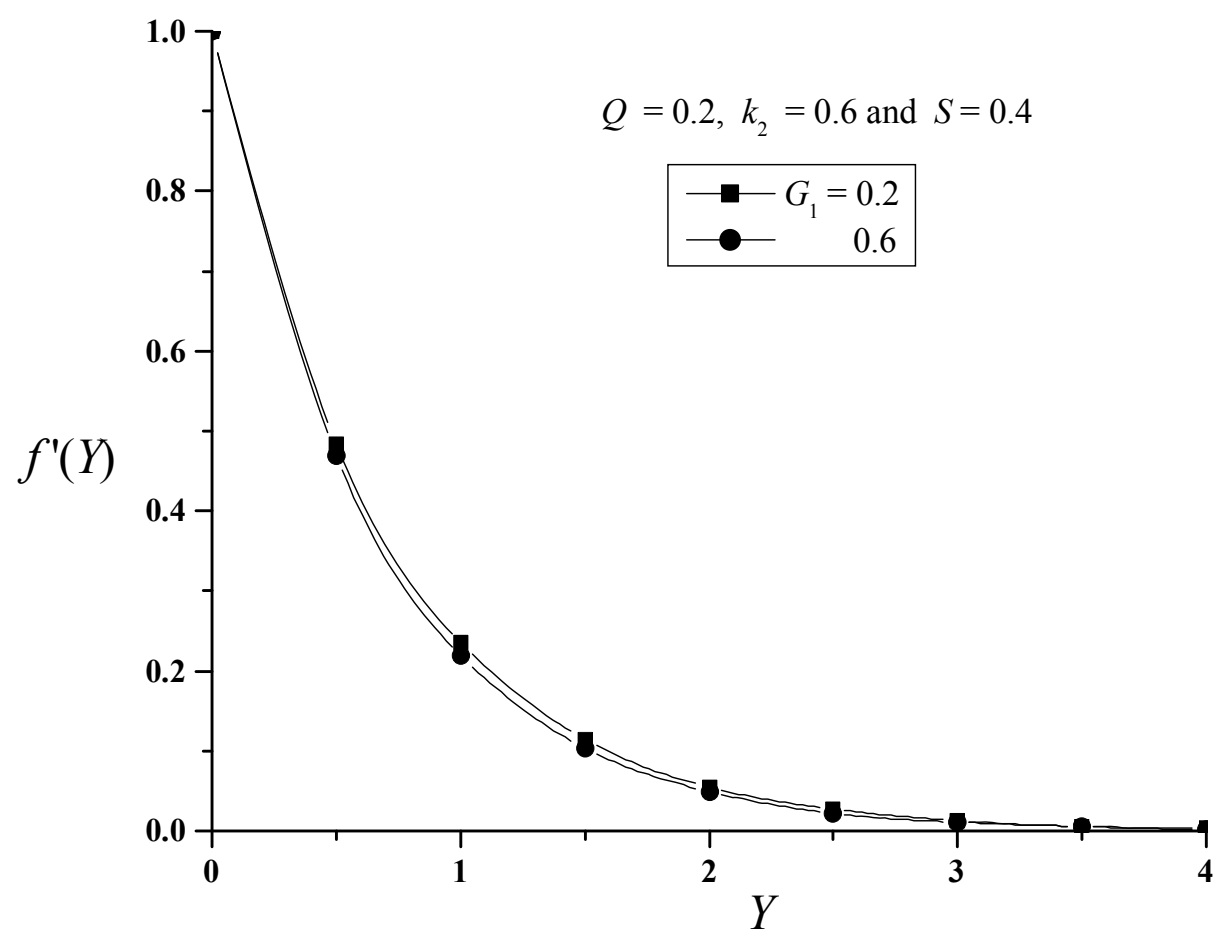

Fig.4. Plot of $f^{\prime}(Y)$ versus $Y$ for different values of microrotational coupling parameter $G_{l}$.

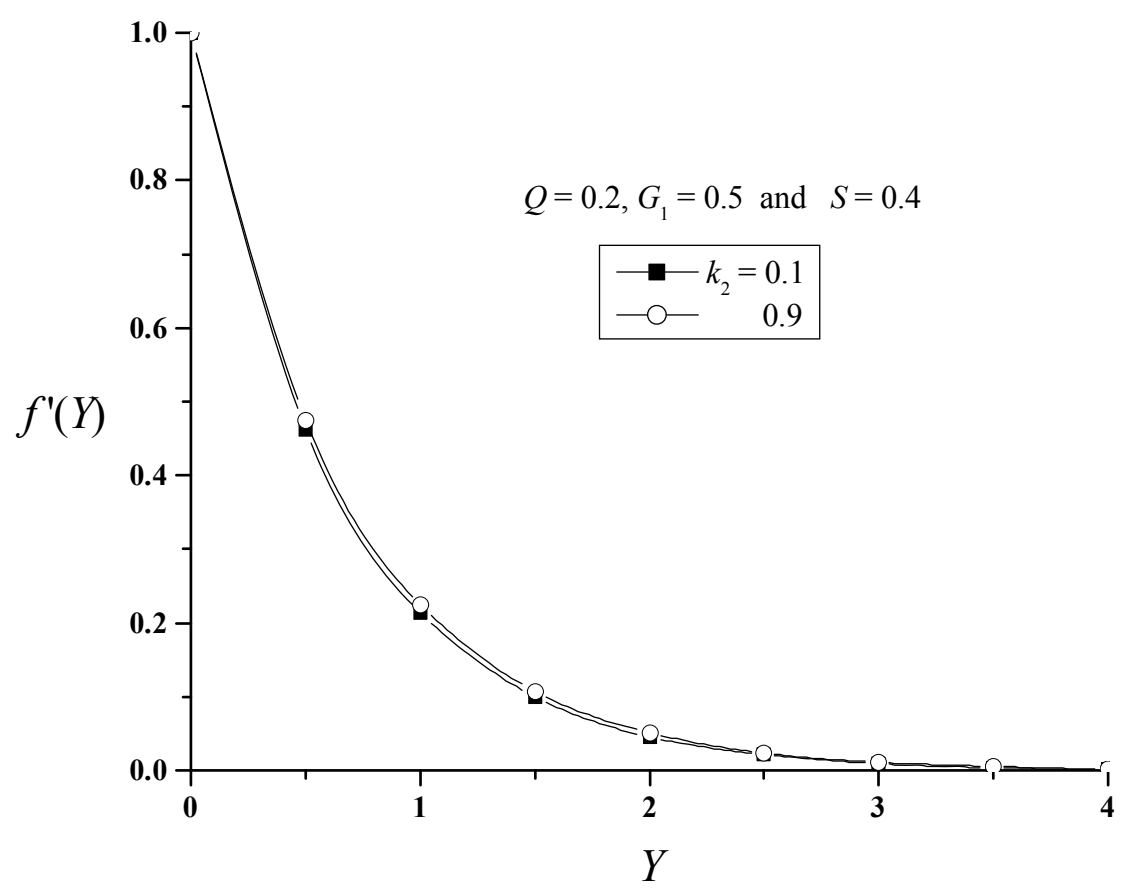

Fig.5. Plot of $f^{\prime}(Y)$ versus $Y$ for different values of microrotational diffusivity parameter $k_{2}$. 
Like $f^{\prime}(Y), h(Y)$ is also a decreasing function of $Y$. The effect of increasing $Q$ on $h(Y)$ is to decrease $h(Y)$. This is due to the fact that $h(Y)$ is an exponentially decreasing function (see Eq.(2.19). Compared to the effect of $Q$ on $h(Y)$, the effect of $S$ on $h(Y)$ is not so pronounced. This is shown in Figs 6 and 7.

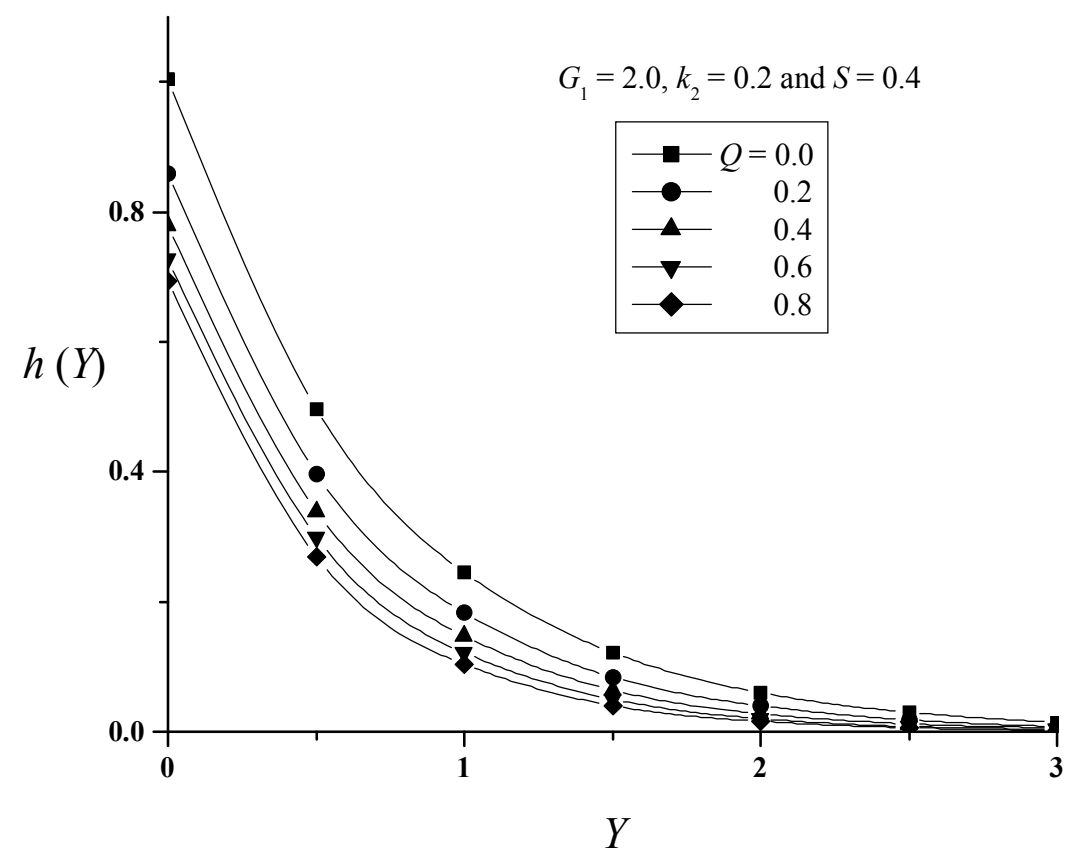

Fig.6. Plot of $h(Y)$ versus $Y$ for different values of Q.

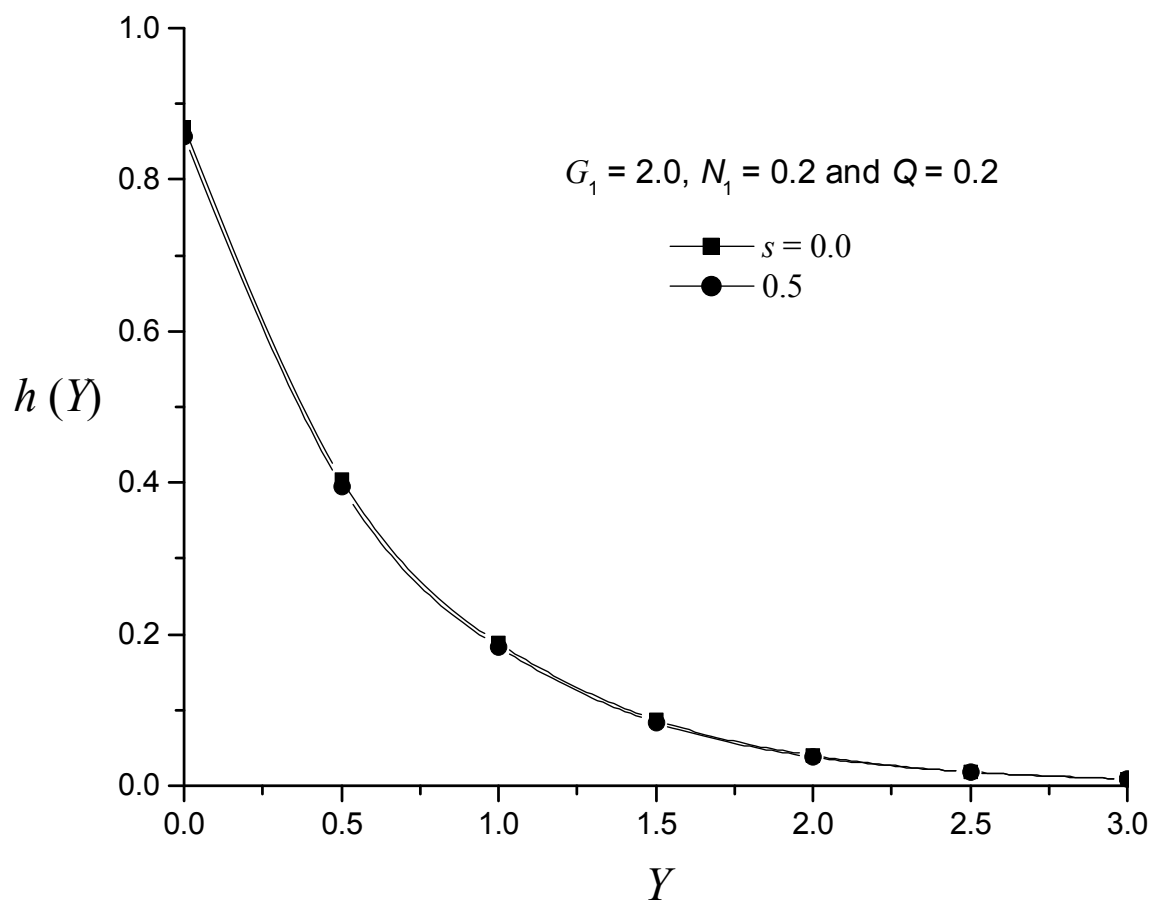

Fig.7. Plot of $h(Y)$ versus $Y$ for different values of $s$. 


\section{Acknowledgments}

The author Dr. U.S. Mahabaleshwar wishes to thank Bharat Ratna Prof. Dr. C.N.R. Rao F.R.S, Hon'ble Chairman VGST and Dr. S. Anant Raj, Consultant, Department of IT, BT Science \& Technlogy, Government of Karnataka, India, for supporting this work under Seed Money to Young Scientists for Research (\# VGST/SMYSR/GRD-304/2013-14).

\section{Nomenclature}

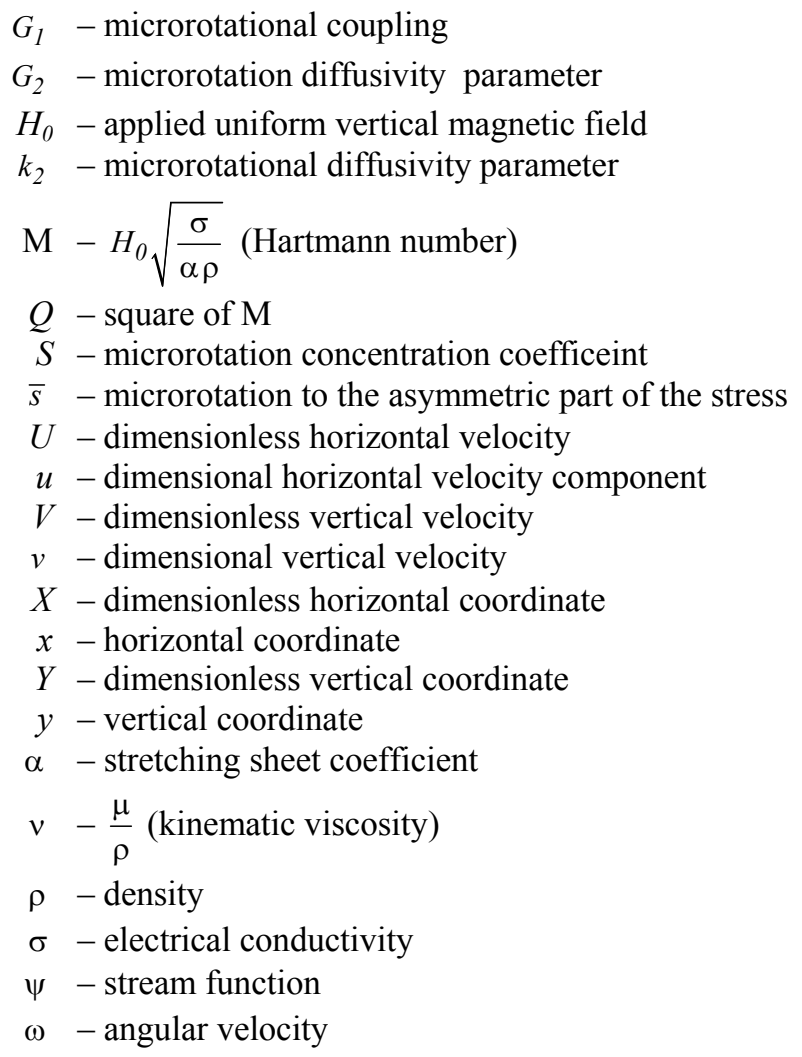

\section{References}

Abo-Eldahab E.M. and Ghonaim A.F. (2003): Convective heat transfer in an electrically conducting micropolar fluid at a stretching surface with uniform free stream. - App. Math. Comp., vol.137, No.2, pp.323-336.

Agarwal R.S., Rama B. and Balaji A.V.S. (1989): Finite element solution of flow and heat transfer of a micropolar fluid a over stretching sheet. - Int. J. Engg. Sci., vol.2, pp.1421-1428.

Bhargava R., Kumar L. and Takhar H.S. (2003): Finite element solution of mixed convection micropolar flow driven by a porous stretching sheet. - Int. J. Engg. Sci., vol.41, pp.2161-2178.

Eldabe N.T., Elshehawey E.F., Elbarbary E.M.E. and Elgazery N.S. (2005): Chebyshev finite diffrence method for MHD flow of a micropolar fluid past a stretching sheet with heat transfer. - Appl. Maths. Comp., vol.160, No.2, pp.437-450.

Hady F.M. (1996): Short communication on the solution of heat transfer to micropolar fluid from a non-isothermal stretching sheet with injection. - Int. J. Num. Meth. Heat Fluid Flow, vol.6, pp.99-104. 
Hassanien I.A. (1998): Boundary layer flow and heat transfer on a continuous on a continuous accelerated sheet extruded in an ambient micropolar fluid. - Int. J. Comm. Heat Mass Transfer, vol.25, pp.571-583.

Hassanien I.A. and Gorla R.S.R. (1990): Heat transfer to micropolar fluid from a non-isothermal stretching sheet with suction and blowing. - Acta Mech., vol.84, pp.191-199.

Heruska M.H., Watson L.T. and Sankara K.K. (1986): Micropolar flow past a porous stretching sheet. - Comp. Fluids, vol.14, pp.117-129.

Kelson N.A. and Desseaux A. (2001): Effect of surface conditions on flow of a micropolar fluid driven by a porous stretching sheet. - Int. J. Engg. Sci., vol.39, pp.1881-1897.

Kelson N.A. and Farrell T.W. (2001): Micropolar flow over porous stretching sheet with strong suction or injection.Int. J. Comm. Heat Mass Transfer, vol.28, No.4, pp.479-488.

Lukaszewicz (1999): Micropolar fluid theory and applications. - Birkhauser Boston, M.A., USA.

Mohammadein A.A. and Gorla R.S.R. (2000): Heat transfer in micropolar fluid over a stretching sheet with viscous dissipation and internal heat generation. - Int. J. Num. Math. Heat Fluid Flows, vol.11, No.1, pp.50-58.

Nazar R., Amin N., Filip D. and Pop I. (2004): Stagnation point flow of micropolar fluid towards stretching sheet. Int. J. Non-Linear Mech., vol.39, pp.1227-1235.

Rajagopal K.R., Na T.Y. and Gupta A.S. (1984): Flow of a viscoelastic fluid over a stretching sheet. - Rheo. Acta, vol.23, pp.213-215.

Seddeek M.A. (2001): Effect of Hall and ion-slip currents on magneto-micropolar fluid and heat transfer over a nonisothermal stretching sheet with suction and blowing. - Proc. Roy. Soc. Lond. A, vol.457, pp.3039-3050.

Siddheshwar P.G. and Mahabaleswar U.S. (2005): Effects of radiation and heat source on MHD flow of a viscoelastic liquid and heat transfer over a stretching sheet. - Int. J. Non-Linear Mech., vol.40, pp.807-820.

Received: January 10, 2014

Revised: March 2, 2015 